\title{
Empleo del Análisis de Redes Sociales para el estudio de la estructura de la relación entre definiciones del concepto estrategia elaboradas entre los años 1962 y 2003
}

\author{
Guillermo Armando Ronda Pupo. Universidad de Holguín, Cuba ${ }^{1}$ \\ Emilio López Zapata. Universidad de Málaga, España
}

\section{Resumen}

El presente trabajo se realizó con el objetivo de determinar la estructura de la relación entre las definiciones del concepto de estrategia abordadas por diferentes autores desde su surgimiento en la década del 60 del siglo XX.

Para realizar el mismo se parte de la selección de 38 definiciones elaboradas por diferentes autores. Se realizó la deconstrucción de cada definición para escoger los términos claves empledos en cada una. Luego se elaboró una matriz de afiliación utilizando como unidad de observación cada autor y como variables los términos claves seleccionados de cada definición. Se asignó (1) a la presencia del témino en la definición y (0) a la ausencia del mismo. Mediante el empleo del programa Netdraw se obtuvo la estructura de las relaciones entre términos claves.

Se empleó la prueba Kappa Cohen para determinar el coeficiente de concordancia entre cada par de autores que abordaron la definición del concepto estrategia, luego se construyó una matriz de incidencia, para lo cual se asumió que existe relación (1) si y sólo si existe un coeficiente de concordancia bueno $(K>0.40)$ y no existe relación $(0)$ si ocurre lo contrario $(K<0.40)$, y luego se obtiene la estructura a través de Netdraw.

Palabras clave: concepto estrategia - kappa Cohen - deconstrucción de conceptos - coeficiente de de consenso.

\begin{abstract}
The present work was carried out to determine the structure of relations among the definition of the concept "strategy" that have been elaborated by authors from its origin in the decade of the sixties during the twentieth century.

For its execution, thirty-eight definitions were taken as a sample. Each of them was deconstructed to identify the key terms used by the authors. Once it was accomplished, a filiations's matrix was elaborated using the authors as the observation unit and the definition's key terms as variables. Then (1) was assigned to the presence of the term in the definition and zero to the absence of it. Finally, the structure of the relations among key terms was obtained through the program Net Draw.
\end{abstract}

The Kappa Cohen test was applied to determine the coefficient of concordance between each pair of authors who dealt with the definition of the concept of Strategy, then a incidence matrix was built assuming that there is 1 if only there is a coefficient of concordance $(K>0.40)$ and there is no relation $(0)$ if the opposite

\footnotetext{
${ }^{1}$ Enviar correspondencia a: (Guillermo Armando Ronda Pupo rondapupo@yahoo.com y grpupo@uci.cu).
} 
REDES- Revista hispana para el análisis de redes sociales

Vol.14,\#9, Junio de 2008

http: // revista-redes.rediris.es

occurs $(K<0.40)$. Finally, the structure of relations among the authors was obtained through Net Draw.

Key words: strategy concept - Kappa Cohen - Concept deconstruction Consensus coefficient.

\section{I ntroducción}

El término estrategia es de origen griego. Estrategeia, estrategos o el arte del general en la guerra, procede de la fusión de dos palabras: stratos (ejército) y agein (conducir, guiar).

El concepto "estrategia" se tiene como referencia primaria al año 300 antes de nuestra era, con el libro de Tzun Tzu (Tzu, 1883) “El Arte de la Guerra”, en el cual, basándose en las experiencias de las antiguas campañas, establece recomendaciones sobre cómo hacer la guerra, la organización para los ejércitos, el empleo de las armas, así como explicar la influencia de la geografía y la política en la guerra.

El mundo helénico, se caracterizó por las observaciones y escritos de Jenofontes y de Tucidides quienes marcaron el inicio de la estrategia como ciencia militar; en Roma Polibio, Plutarco y Tito Livio relataron sus experiencias estratégicas. Se considera al Emperador Julio César el máximo representante de esta era.

Con el Renacimiento aparece la figura de Nicolás de Maquiavelo (Machiavelli, 1998), que escribe su libro "El Principe" donde hace recomendaciones importantes sobre la composición de los ejércitos para poder asegurar la existencia del Estado.

Con la Revolución francesa y todo el gran ciclo revolucionario burgués del siglo XIX surge uno de los modernos artífices de la estrategia, Karl Von Clausewitz (Clausewitz, 1977), el que en su obra "De la Guerra", sistematiza el conocimiento acumulado hasta entonces sobre la guerra y su técnica; el pensamiento de este autor tuvo influencia hasta poco después de las Guerras Mundiales.

Los creadores y modernizadores de la estrategia llamada la estrategia total son Liddell Hart, Fuller, Collins y sobre todo el Francés Beaufre. Dentro de esta concepción estratégica han surgido hombres como August Von der Heydte con su excelente obra "La Guerra Irregular Moderna" que describe cómo se ha pasado a una concepción totalizadora de la estrategia, en la que el objetivo de ésta es "básicamente, provocar cierta reacción psicológica de parte del adversario". 
REDES- Revista hispana para el análisis de redes sociales

Vol.14,\#9, Junio de 2008

http: //revista-redes.rediris.es

El concepto "estrategia" se introduce en el campo académico desde 1944 con la teoría de los juegos por Von Newman y Morgerstern (Newman \& Morgenstern, 1964) , y en el campo de la teoría de la dirección, se anuncia en Estados Unidos de América en el año 1962 y expuesto en el libro de Igor Ansoff (1991), "Estrategias Corporativas".

En 1987 aparece el concepto en el campo de la pedagogía, entronizado con diferentes matices (estrategia educativa, estrategia metacognitiva, estrategia de aprendizaje).

Es importante resaltar que a pesar que no existe una definición universalmente aceptada sobre el concepto estrategia existe consenso en que la estrategia permite tomar las decisiones para determinar los recursos que la organización destinará a sus principales acciones y la efectividad del funcionamiento, que es un proceso de pensamiento que establece trayectorias, posiciones y perspectivas para la organización, que tiene un razonamiento singular, que es un fenómeno objetivo en el cual las condiciones surgen y que presenta una complejidad dinámica.

En el presente trabajo se presenta un estudio sobre la definición del concepto estrategia desde la perspectiva del análisis de redes sociales.

\section{Materiales y métodos}

La dirección estratégica, como campo de producción científica, ha sido abordada por muchos autores desde varias perspectivas. En 1980 se publicó el artículo de (Bracker, 1980) relacionado con la evolución del concepto estrategia. En el mismo presenta un estudio cienciométrico a partir de regularidades en definiciones de dirección estratégica y, a partir del mismo, propone una nueva definición.

A partir de ese momento comenzó un incremento de la producción científica relacionada con la investigación de la dirección estratégica como campo teórico; a través del estudio cienciométrico de dicha producción científica se pueden apreciar tres tendencias fundamentales (ver ilustración 1): la primera tendencia está relacionada con el estudio cualitativo de la dirección estratégica como un constructo para determinar la estructura, dimensiones y su evolución histórica. En esta tendencia se destacan los estudios de los autores (Bracker, 1980), (Feurer \& Chaharbaghi, 1995), (Boyd, Gove, \& Hitt, 2005), (Fréry, 2006), y (Furrer, Thomas, \& Goussevskaia, 2007). 
REDES- Revista hispana para el análisis de redes sociales

Vol.14,\#9, Junio de 2008

http: // revista-redes.rediris.es

La segunda tendencia está relacionada con el empleo de métodos estadísticos para determinar patrones, grupos y tendencias del estudio de la dirección estratégica. En esta tendencia se destacan los trabajos presentados por (David J \& Shook, 1996), (Hulland, 1999), (Hoetker, 2005) y (Hahn \& Doh, 2006).

La tercera tendencia está relacionada con estudios cienciométricos de la producción científica relacionada con la dirección estratégica, (Ramos-Rodriguez \& RuizNavarro, 2004), este interesante trabajo tiene la limitación de presentar sólo el estudio bibliométrico de la producción científica sobre la dirección estratégica en la Strategic Management J ournal, este estudio fue ampliado por el trabajo presentado por (Nerur, Rasheed, \& Natarajan, 2008), quienes abordan el tema desde la perspectiva de la producción científica de varias revistas especializadas sobre estrategia y management en general.

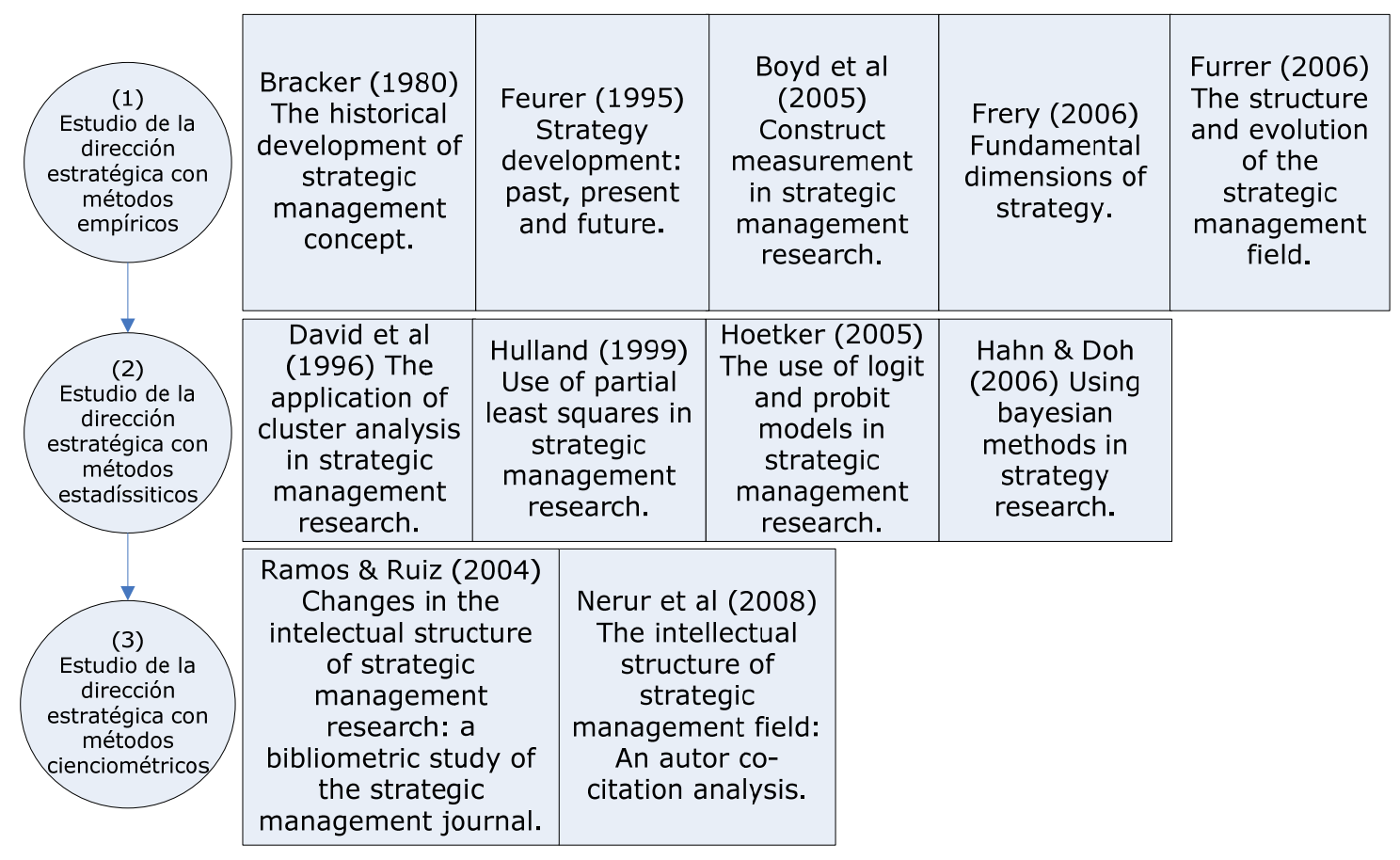

I lustración 1. Principales tendencias de la producción científica del campo de estudio de la dirección estratégica.

En el trabajo se presenta una primera aproximación de la estructura de la dirección estratégica a partir de un estudio de la producción científica relacionada con la definición del concepto de estrategia desde la perspectiva del análisis de redes sociales. 
REDES- Revista hispana para el análisis de redes sociales

Vol.14,\#9, Junio de 2008

http: // revista-redes.rediris.es

La ventaja principal que brinda el empleo del análisis de redes sociales para el estudio de este campo específico radica en que permite visualizar la estructura de las relaciones entre las diferentes definiciones aportadas por los autores que han abordado la estrategia empresarial desde sus inicios y, a partir de la misma, observar los elementos esenciales caraterizan la dirección estratégica y sus tendencias.

La principal diferencia que singulariza el estudio que se presenta es el trabajo de las matrices y el empleo del índice de Kappa Cohen para determinar la relación entre definiciones.

El trabajo pretende responder a las siguientes interrogantes de investigación:

¿Cómo determinar y graficar la estructura de las relaciones entre las definiciones del concepto estrategia, en el campo empresarial, desde sus inicios?

¿Qué información sería necesaria para facilitar la determinación de la existencia de relaciones entre las definiciones del concepto estrategia que han sido elaboradas por autores en tiempo y espacios diferentes?

¿Cómo graficar la estructura de las relaciones entre definiciones, autores y términos claves empleados teniendo en cuenta la diversidad y dispersión de la definicón del concepto estrategia? 
REDES- Revista hispana para el análisis de redes sociales

Vol.14,\#9, Junio de 2008

http://revista-redes.rediris.es

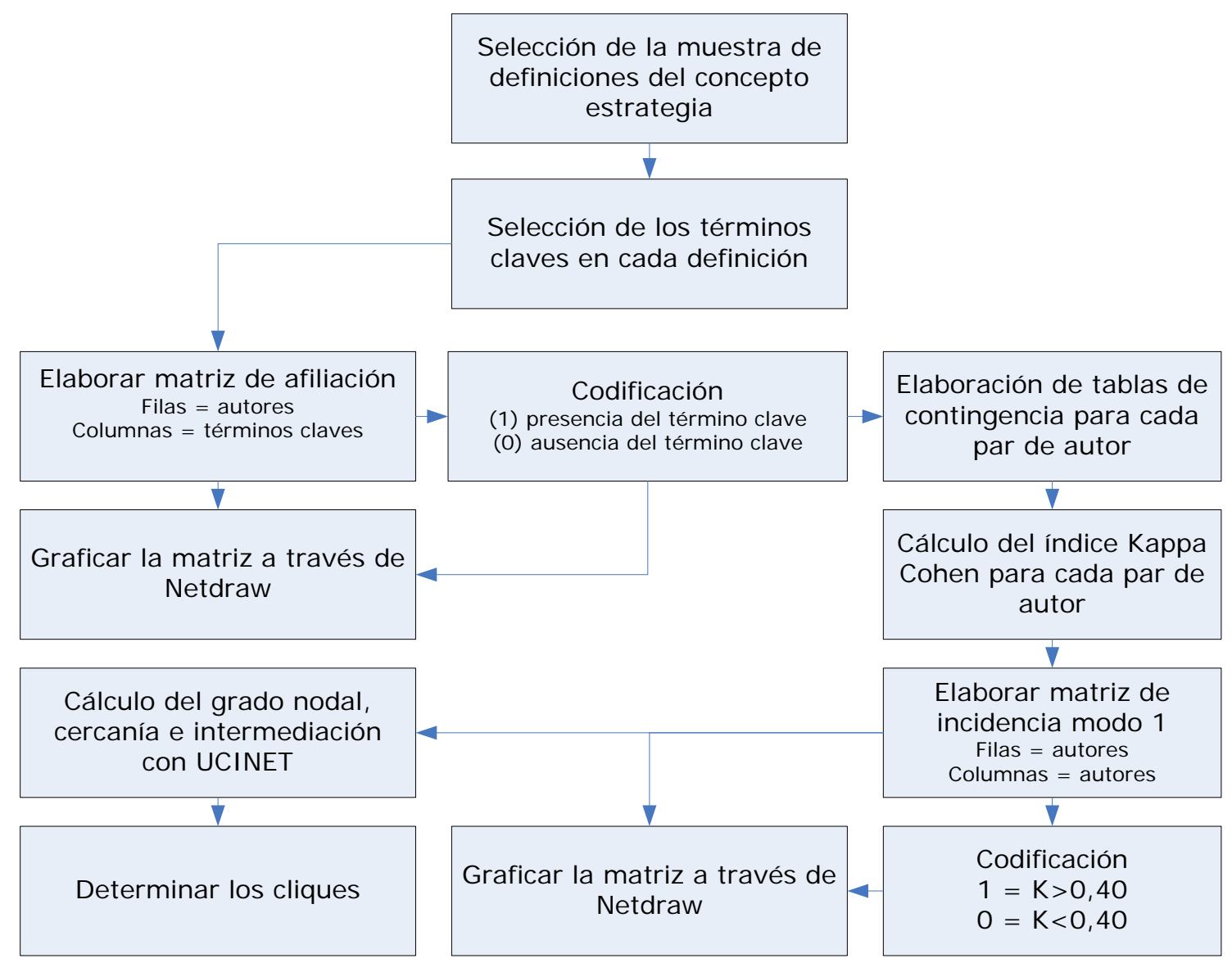

I lustración 2. Lógica seguida durante la investigación.

Para la realización del trabajo se siguió la lógica que se muestra en la ilustración 2. Primeramente se seleccionaron 38 definiciones del concepto estrategia aportados por autores entre los años 1962 y el 2003, ambos inclusive, para lo cual se realizó una revisión de una amplia literatura relacionada con el tema (ver tabla 1). 
REDES- Revista hispana para el análisis de redes sociales

Vol.14,\#9, Junio de 2008

http: // revista-redes.rediris.es

\begin{tabular}{|c|c|c|}
\hline Autor(es) & Año & Definición \\
\hline $\begin{array}{l}\text { Alfred Chandler y } \\
\text { Kenneth Andrews }\end{array}$ & 1962 & $\begin{array}{l}\text { La determinación conjunta de objetivos de la empresa y de las } \\
\text { líneas de acción para alcanzarlas. }\end{array}$ \\
\hline $\begin{array}{l}\text { Andrews (Andrews, } \\
\text { 1962) }\end{array}$ & 1962 & $\begin{array}{l}\text { Patrón de las de los principales objetivos, propósitos o metas y las } \\
\text { políticas y planes esenciales para lograrlos, establecidos de tal } \\
\text { manera que definan en qué clase de negocio la empresa está o } \\
\text { quiere estar y qué clase de empresa es o quiere ser. }\end{array}$ \\
\hline $\begin{array}{l}\text { Alfred Chandler } \\
\text { (Chandler, 1962) }\end{array}$ & 1962 & $\begin{array}{l}\text { Determinación de las metas y objetivos de una empresa a largo } \\
\text { plazo, las acciones a emprender y la asignación de recursos } \\
\text { necesarios para lograr dichas metas. }\end{array}$ \\
\hline $\begin{array}{l}\text { Drucker (Drucker, } \\
1954 \text { ) }\end{array}$ & 1962 & $\begin{array}{l}\text { Proceso continuo de hacer presente las decisiones empresariales } \\
\text { sistemáticamente con le mayor conocimiento de su futuro; la } \\
\text { organización sistemática de los esfuerzos por llevar adelante estas } \\
\text { decisiones; y la medición de los resultados de éstas contra las } \\
\text { expectativas a través de una retroalimentación organizada. }\end{array}$ \\
\hline Leontiev (Leontiev, 1970) & 1970 & $\begin{array}{l}\text { Lograr una visión más amplia y lejana en el horizonte temporal, } \\
\text { destinado a prever y organizar el crecimiento y la diversificación de } \\
\text { las actividades de la empresa y su conjunto. }\end{array}$ \\
\hline $\begin{array}{l}\text { Tabatorny y Jarniou } \\
\text { (Tabatorny \& Jarniou, } \\
\text { 1975) }\end{array}$ & 1975 & $\begin{array}{l}\text { Conjunto de decisiones que determinan la coherencia de las } \\
\text { iniciativas y reacciones de la empresa frente a su entorno. }\end{array}$ \\
\hline $\begin{array}{l}\text { Igor Ansoff (IGOR } \\
\text { ANSOFF, 1991) }\end{array}$ & 1976 & Dialéctica de la empresa con su entorno. \\
\hline $\begin{array}{l}\text { Humble (Humble, } \\
\text { 1977) }\end{array}$ & 1977 & $\begin{array}{l}\text { Sistema dinámico que busca integrar la necesidad que tiene la } \\
\text { compañía de esclarecer u obtener sus metas de utilidades u } \\
\text { crecimiento, con la necesidad que siente el gerente de contribuir y } \\
\text { de auto desarrollarse. }\end{array}$ \\
\hline $\begin{array}{l}\text { Hoffer y Schendel } \\
\text { (Schendel \& Hofer, } \\
\text { 1979) }\end{array}$ & 1979 & $\begin{array}{l}\text { Características básicas del match que una organización realiza con } \\
\text { su entorno. }\end{array}$ \\
\hline $\begin{array}{l}\text { Michael Porter } \\
\text { (PORTER, 1991) }\end{array}$ & 1982 & $\begin{array}{l}\text { Desarrollar una amplia fórmula de cómo la empresa va a competir, } \\
\text { cuáles deben ser sus objetivos y qué políticas serán necesarias } \\
\text { para alcanzar tales objetivos. }\end{array}$ \\
\hline Ohmae (Ohmae, 1982) & 1982 & $\begin{array}{l}\text { Comportamiento por el que una corporación se diferencia } \\
\text { positivamente de sus competidores, usando los puntos fuertes } \\
\text { relativos de la corporación para satisfacer mejor las necesidades } \\
\text { del consumidor. }\end{array}$ \\
\hline $\begin{array}{l}\text { Menguzzato y Renau } \\
\text { (Menguzzatto \& } \\
\text { Renau, 1994) }\end{array}$ & 1984 & $\begin{array}{l}\text { Explicita los objetivos generales de la empresa y los cursos de } \\
\text { acción fundamentales, de acuerdo con los medios actuales y } \\
\text { potenciales de la empresa, a fin de lograr la inserción de ésta en el } \\
\text { medio socioeconómico. }\end{array}$ \\
\hline Quinn (Quinn, 1985) & 1985 & $\begin{array}{l}\text { De una organización, las políticas y acciones secuenciales hacia un } \\
\text { todo cohesionado. Una estrategia bien formulada ayuda al } \\
\text { "mariscal" a coordinar los recursos de la organización hacia una } \\
\text { posición "única, viable", basadas en sus competencias relativas } \\
\text { internas, anticipando los cambios en el entorno y los movimientos } \\
\text { contingentes de los "oponentes inteligentes". }\end{array}$ \\
\hline $\begin{array}{l}\text { Chiavenato } \\
\text { (Chiavenato, 1986) }\end{array}$ & 1986 & $\begin{array}{l}\text { Manera como una empresa intenta aplicar una determinada } \\
\text { estrategia para alcanzar los objetivos propuestos. Es generalmente } \\
\text { la planeación global y a largo plazo. }\end{array}$ \\
\hline $\begin{array}{l}\text { Halten citado en } \\
\text { (Ronda Pupo, 2003) }\end{array}$ & 1987 & $\begin{array}{l}\text { Proceso a través del cual una organización formula objetivos, y } \\
\text { está dirigido a la obtención de los mismos. Estrategia es el medio, } \\
\text { la vía, es el cómo para la obtención de los objetivos de la } \\
\text { organización. Es el arte (maña) de entremezclar el análisis interno } \\
\text { y la sabiduría utilizada por los dirigentes para crear valores de los } \\
\text { recursos y habilidades que ellos controlan. Para diseñar una } \\
\text { estrategia exitosa hay dos claves; hacer lo que hago bien y }\end{array}$ \\
\hline
\end{tabular}


REDES- Revista hispana para el análisis de redes sociales

Vol.14,\#9, Junio de 2008

http: // revista-redes.rediris.es

\begin{tabular}{|c|c|c|}
\hline Autor(es) & Año & Definición \\
\hline & & escoger los competidores que puedo derrotar. \\
\hline $\begin{array}{l}\text { Weirich (Weirich, } \\
\text { 1993) }\end{array}$ & 1990 & $\begin{array}{l}\text { Sistema de administración complejo que integra muchas } \\
\text { actividades administrativas claves, de manera sistemática, dirigida } \\
\text { hacia el logro eficaz y eficiente de los objetivos organizacionales e } \\
\text { individuales. }\end{array}$ \\
\hline $\begin{array}{l}\text { Reyes Ponce (Reyes } \\
\text { Ponce, 1990) }\end{array}$ & 1990 & $\begin{array}{l}\text { Técnica que busca obtener resultados de máxima eficiencia, por } \\
\text { medio de la coordinación de las personas, las cosas y sistemas que } \\
\text { conforman una empresa. }\end{array}$ \\
\hline $\begin{array}{l}\text { Harold Koontz } \\
\text { (Weirich, 1993) }\end{array}$ & 1990 & $\begin{array}{l}\text { Programas generales de acción que llevan consigo compromisos de } \\
\text { énfasis y recursos para poner en práctica una misión básica. Son } \\
\text { patrones de objetivos, los cuales se han concebido e iniciado de tal } \\
\text { manera, con el propósito de darle a la organización una dirección } \\
\text { unificada. }\end{array}$ \\
\hline $\begin{array}{l}\text { Fred David (David, } \\
\text { 1991) }\end{array}$ & 1991 & $\begin{array}{l}\text { Llevar a cabo estrategias que obtengan beneficios de sus fortalezas } \\
\text { internas, aprovechar las oportunidades externas, mitigar las } \\
\text { debilidades internas y evitar o aminorar el impacto de las } \\
\text { amenazas externas. En este proceso radica la esencia de la } \\
\text { dirección estratégica. }\end{array}$ \\
\hline $\begin{array}{l}\text { Robert Cope (Cope, } \\
\text { 1991) }\end{array}$ & 1991 & Exploración en busca de dirección para toda la empresa. \\
\hline $\begin{array}{l}\text { Enrique Ogliastri } \\
\text { (Ogliastri, 1992) }\end{array}$ & 1992 & $\begin{array}{l}\text { Conjunto de contribuciones encaminadas a la orientación general } \\
\text { de una empresa... y cuyo propósito esencial radica en lograr una } \\
\text { ventaja competitiva sostenible en el largo plazo. }\end{array}$ \\
\hline $\begin{array}{l}\text { Harper y Linch (Harper } \\
\& \text { Linch, 1992) }\end{array}$ & 1992 & $\begin{array}{l}\text { Sistema dinámico de anticipación en el que se destacan y agrupan } \\
\text { los aspectos estratégicos diferenciadores empresariales en el } \\
\text { marco de un entorno abierto procurando desarrollar una cultura } \\
\text { empresarial que apoye las ventajas competitivas que la empresa } \\
\text { tiene. }\end{array}$ \\
\hline $\begin{array}{l}\text { George Morrisey } \\
\text { (Morrisey, 1993) }\end{array}$ & 1993 & $\begin{array}{l}\text { Aquello donde se dirige una empresa en el futuro en vez de cómo } \\
\text { llegar ahí; entonces define la estrategia como la dirección en la que } \\
\text { una empresa necesita avanzar para cumplir con su misión. }\end{array}$ \\
\hline $\begin{array}{l}\text { Robbins } \\
\text { (CHAMBERLAIN, } \\
\text { BLACKWELL, } \\
\text { FINEBERG, ROBBINS, } \\
\text { \& SAHAKIAN, 2006) }\end{array}$ & 1993 & $\begin{array}{l}\text {...la forma en que la empresa habrá de alcanzar sus objetivos, dado } \\
\text { que es la función de una serie de programas de soporte primarios y } \\
\text { secundarios; pero, sí definen la estructura de trabajo que ha de } \\
\text { servir de guía a pensamientos y actividades. Su utilidad práctica y } \\
\text { su importancia como guía del direccionamiento, justifican de todas } \\
\text { maneras, la separación de las estrategias como un tipo de plan con } \\
\text { propósitos de análisis. }\end{array}$ \\
\hline Serna (Serna, 1994) & 1994 & $\begin{array}{l}\text { Proceso mediante el cual quienes toman decisiones en una } \\
\text { organización obtienen, procesan y analizar información pertinente } \\
\text { interna y externa, con el fin de evaluar la situación presente de la } \\
\text { empresa, así como su nivel de competitividad con el propósito de } \\
\text { anticipar y decidir sobre el direccionamiento de la institución hacia } \\
\text { el futuro. }\end{array}$ \\
\hline $\begin{array}{l}\text { Samuel Certo y Paul } \\
\text { Peters (Certo, 1994) }\end{array}$ & 1994 & $\begin{array}{l}\text { Proceso continuado, reiterativo y transfuncional dirigido a } \\
\text { mantener a una organización en su conjunto, acoplada de manera } \\
\text { apropiada con el ambiente en el que se desenvuelve. }\end{array}$ \\
\hline $\begin{array}{l}\text { Greg Bounds (Bounds, } \\
\text { Yorks, Adams, \& } \\
\text { Ranney, 1994) }\end{array}$ & 1994 & $\begin{array}{l}\text { Sustentación y coordinación de esfuerzos para lograr objetivos a } \\
\text { largo plazo. }\end{array}$ \\
\hline $\begin{array}{l}\text { Lambin citado en } \\
\text { (Ronda Pupo, 2003) }\end{array}$ & 1994 & $\begin{array}{l}\text { Orientar la empresa hacia oportunidades económicas atractivas } \\
\text { para ella (y para la sociedad), es decir, adaptadas a sus recursos y } \\
\text { su saber hacer, y que ofrezcan un potencial atrayente de } \\
\text { crecimiento y rentabilidad... (Para lo cual deberá) precisar la } \\
\text { misión de la empresa, definir sus objetivos, elaborar sus } \\
\text { estrategias de desarrollo y velar por mantener una estructura } \\
\text { racional en su cartera de productos mercados. }\end{array}$ \\
\hline $\begin{array}{l}\text { Odiorne (Odiorne, } \\
\text { 1995) }\end{array}$ & 1995 & $\begin{array}{l}\text { Proceso en el cual los gerentes superiores y subordinados de una } \\
\text { organización identifican conjuntamente sus metas comunes, }\end{array}$ \\
\hline
\end{tabular}


REDES- Revista hispana para el análisis de redes sociales

Vol.14,\#9, Junio de 2008

http: // revista-redes.rediris.es

\begin{tabular}{|c|c|c|}
\hline Autor(es) & Año & Definición \\
\hline & & $\begin{array}{l}\text { definen las principales áreas de responsabilidad de cada persona } \\
\text { en términos de los resultados que se esperan de él, o de ella, y } \\
\text { usan estas mediciones como pautas para operar la unidad y } \\
\text { evaluar la contribución de cada uno de sus miembros... }\end{array}$ \\
\hline $\begin{array}{l}\text { Londoño citado en } \\
\text { (Ronda Pupo, 2003) }\end{array}$ & 1995 & $\begin{array}{l}\text { Programa general de acción y un despliegue implícito de empeños } \\
\text { y recursos para obtener objetivos trascendentes. La estrategia } \\
\text { define el qué, cuándo, cómo, dónde y para qué de los recursos, } \\
\text { lógicamente promoviendo su plena contribución al desarrollo del } \\
\text { potencial de la empresa. }\end{array}$ \\
\hline $\begin{array}{l}\text { Bervejillo citado en } \\
\text { (López, 2005) }\end{array}$ & 1996 & $\begin{array}{l}\text { Método complejo capaz de sustentar el diseño de estrategias en un } \\
\text { entorno incierto y complejo, apoyado en la prospectiva, y en la } \\
\text { concertación público privada, característica del planeamiento } \\
\text { territorial reciente. }\end{array}$ \\
\hline $\begin{array}{l}\text { Blackerby citado en } \\
\text { (López, 2005) }\end{array}$ & 1996 & $\begin{array}{l}\text { Proceso continuo y sistemático donde las personas toman } \\
\text { decisiones acerca de los resultados futuros que pretenden, como se } \\
\text { logran los resultados y cómo se mide y evalúa el éxito. }\end{array}$ \\
\hline $\begin{array}{l}\text { George Steiner } \\
\text { (STEINER, 1965) }\end{array}$ & 1996 & $\begin{array}{l}\text { Proceso de determinar cuáles son principales objetivos de una } \\
\text { organización y los criterios que presidirán la adquisición, uso y } \\
\text { disposición de recursos en cuanto a la consecución de los referidos } \\
\text { objetivos; éstos, en el proceso de la planificación estratégica, } \\
\text { engloban misiones o propósitos, determinados previamente, así } \\
\text { como los objetivos específicos buscados por una empresa. }\end{array}$ \\
\hline $\begin{array}{l}\text { Henry Mintzberg } \\
\text { (Mintzberg \& Queen, } \\
\text { 1997) }\end{array}$ & 1997 & $\begin{array}{l}\text { Curso de acción definido conscientemente, una guía para enfrentar } \\
\text { una situación. Ploy (Maniobra en español) dirigida a derrotar un } \\
\text { oponente o competidor. Patrón, de comportamiento en el curso de } \\
\text { las acciones de una organización, consistencia en el } \\
\text { comportamiento, aunque no sea intencional. Posición, identifica la } \\
\text { localización de la organización en el entorno en que se mueve (tipo } \\
\text { de negocio, segmento de mercado, etc.) Perspectiva: relaciona a la } \\
\text { organización con su entorno, que la lleva a adoptar determinados } \\
\text { cursos de acción. }\end{array}$ \\
\hline $\begin{array}{l}\text { Hax y Najluf (Hax \& } \\
\text { Majluf, 1997) }\end{array}$ & 1997 & $\begin{array}{l}\text { Actividades críticas de la empresa, proporcionándola un sentido de } \\
\text { unidad, dirección y propósito, así como facilitando los cambios } \\
\text { necesarios inducidos por su entorno. }\end{array}$ \\
\hline $\begin{array}{l}\text { Urich citado en (Del } \\
\text { Mazo Pérez, 1998) }\end{array}$ & 1998 & $\begin{array}{l}\text { Proceso de aprendizaje en el que permanentemente se hacen } \\
\text { supuestos y se toman decisiones tentativas, hasta que el resultado } \\
\text { final, en que se obtiene una solución, se considera satisfactorio. Es } \\
\text { por consiguiente una manera de organizar y ejercitar el talento y la } \\
\text { voluntad de u grupo humano en el examen autocrítica y } \\
\text { multifacético e una organización que enfrenta el problema } \\
\text { complejo y deficientemente difuso e incierto por las constantes } \\
\text { alteraciones que se introducen las interacciones de conglomerados } \\
\text { humanos. }\end{array}$ \\
\hline $\begin{array}{l}\text { Robert Grosse (Grosse, } \\
\text { 2000) }\end{array}$ & 2000 & $\begin{array}{l}\text { Establecimiento de metas y objetivos, así como la traducción de los } \\
\text { planes en programas y el monitoreo para asegurar el cumplimiento } \\
\text { de los objetivos, además, implica la tarea de comunicar y de } \\
\text { mostrar una línea para el empleo general de los recursos. }\end{array}$ \\
\hline $\begin{array}{l}\text { Bartoli y Hernel citado } \\
\text { en (Foleiro, 2005) }\end{array}$ & 2003 & $\begin{array}{l}\text { Intento de mejorar la dirección y la gestión de una organización } \\
\text { utilizando la estrategia para guiar sus acciones pero integrando las } \\
\text { nociones de preparación de la puesta en marcha y de asignación de } \\
\text { recursos, pues el paso de lo estratégico a lo operativo es también } \\
\text { competencia de la DE, así como mantener la correspondencia y } \\
\text { armonía entre ambos. }\end{array}$ \\
\hline
\end{tabular}

Tabla 1. Relación de autores y definiciones del concepto estrategia.

Una vez recopilada la información sobre las definiciones elaboradas sobre el concepto estrategia se realizó la deconstrucción de cada definición determinando en cada una de ellas los términos claves empleados por los autores (ver ilustración 3). 
REDES- Revista hispana para el análisis de redes sociales

Vol.14,\#9, Junio de 2008

http://revista-redes.rediris.es

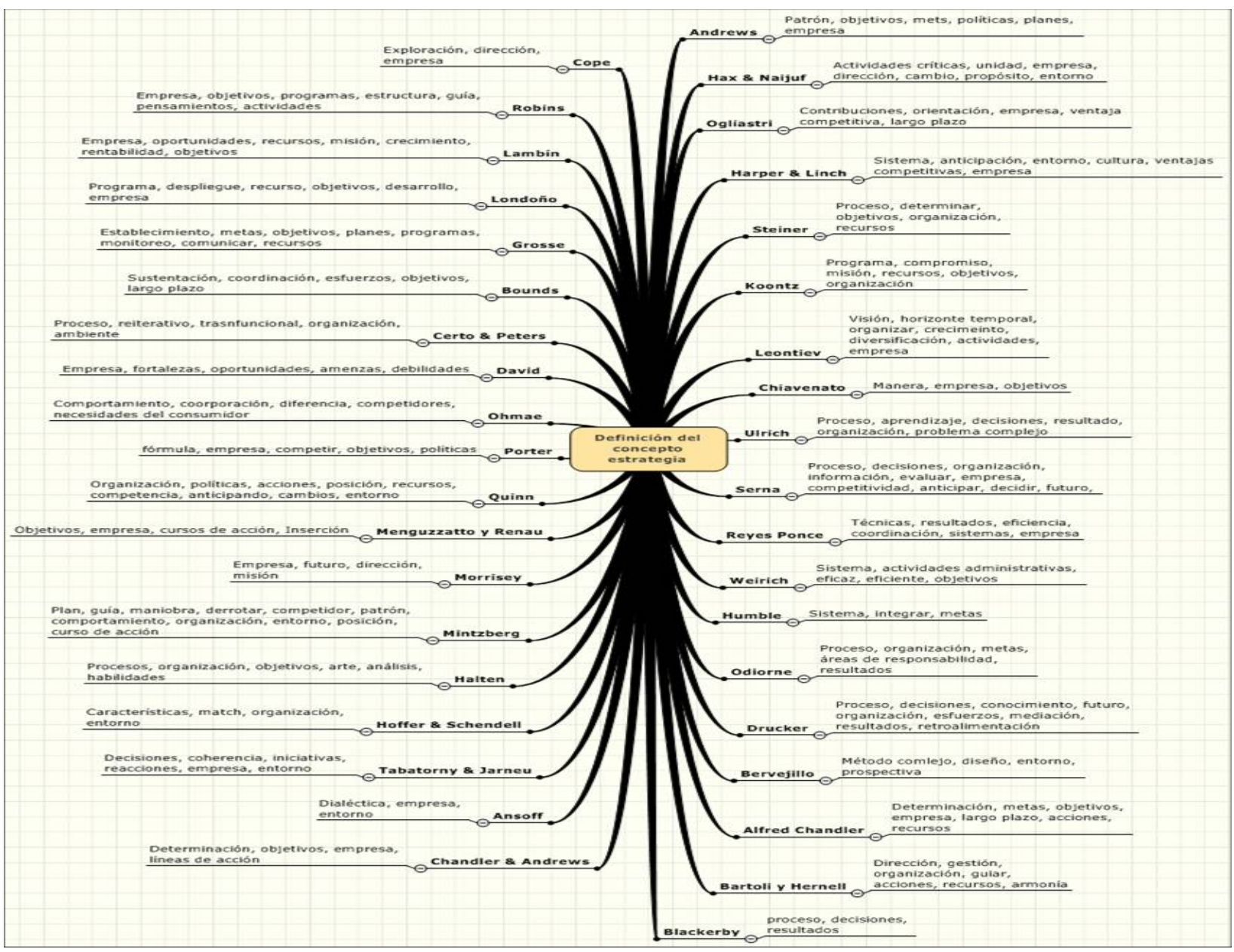

I lustración 3. Mapa de términos claves obtenidos de la deconstrucción de las definiciones del concepto estrategia.

Se elaboró una matriz de afiliación (ver ilustración 4) empleando los autores como unidades de observación y los términos claves empleados por los mismos en la definición como variables.

Se realizó la codificación mediante variables dicotómicas en relación con la presencia o ausencia del término clave en la definición de cada autor. Se asigna (1) a la presencia y (0) a la ausencia. 
REDES- Revista hispana para el análisis de redes sociales

Vol.14,\#9, Junio de 2008

http: // revista-redes.rediris.es

\begin{tabular}{|c|c|c|c|c|c|c|c|c|c|c|c|c|c|}
\hline \multicolumn{13}{|c|}{ 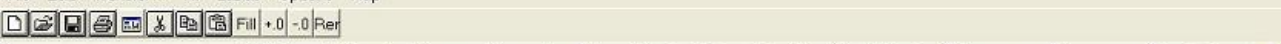 } & \\
\hline & Visión & $\mid \begin{array}{l}\text { Horizontel } \\
\text { temporal }\end{array}$ & & Preveer & Organizar & Crecimiento & Diversificación & Actividades & Empresa & & Proceso & Decisiones ^ & Current cell:: \\
\hline Leontiev & 1 & & 1 & 1 & 1 & 1 & 1 & & 1 & 1 & & $\overrightarrow{0}$ & $\frac{\text { Row }}{\sqrt{0}} \frac{\text { Col: }}{10}$ \\
\hline Drucker & 0 & & 0 & 0 & 0 & 0 & 0 & & 0 & 0 & & 1 & \multirow{2}{*}{ Dimensions } \\
\hline Bartoli y Hernel & 0 & & 0 & 0 & 0 & 0 & 0 & & 0 & 1 & & 0 & \\
\hline Odiorne & 1 & & 1 & 1 & 1 & 1 & 1 & & 1 & 1 & & 1 & $\begin{array}{l}\text { Rows: } \\
\sqrt{38}\end{array}$ \\
\hline Humble & 0 & & 0 & 0 & 0 & 0 & 0 & & 0 & 0 & & 0 & \multirow{2}{*}{$\begin{array}{l}\text { Mode } \\
\text { - Normal } \\
\text { C Symmetric }\end{array}$} \\
\hline Weirich & 0 & & 0 & 0 & 0 & 0 & 0 & & 0 & 0 & & 0 & \\
\hline Reyes Ponce & 0 & & 0 & 0 & 0 & 0 & 0 & & 0 & 1 & & 0 & \\
\hline Serna & 0 & & 0 & 0 & 0 & 0 & 0 & & 0 & 1 & & 1 & \\
\hline Urich & 0 & & 0 & 0 & 0 & 0 & 0 & & 0 & 1 & & 0 & \\
\hline Chiavenato & 0 & & 0 & 0 & 0 & 0 & 0 & & 0 & 1 & & 0 & \\
\hline Alfred Chandler & 0 & & 0 & 0 & 0 & 0 & 0 & & 0 & 1 & & 0 & \\
\hline Bervejillo & 0 & & 0 & 0 & 0 & 0 & 0 & & 0 & 0 & & 0 & \\
\hline Blackerby & 0 & & 0 & 0 & 0 & 0 & 0 & & 0 & 0 & & 1 & \\
\hline Chandler y Andrews & 0 & & 0 & 0 & 0 & 0 & 0 & & 0 & 1 & & 0 & \\
\hline $\begin{array}{l}\text { Igor Ansoff } \\
<\end{array}$ & 0 & & 0 & 0 & 0 & 0 & 0 & & 0 & 1 & & ${ }^{v}$ & \\
\hline Sheet1 & & & & & & & & & & & & & \\
\hline
\end{tabular}

I lustración 4. Parte de la matriz de afiliación partir de los autores y los términos claves empleados en las definiciones del concepto estrategia.

Se empleó el Netdraw para graficar las relaciones entre términos claves y autores que han abordado la definición del concepto estrategia.

Empleando la información de la matriz de afiliación se contruyeron tablas de contingencias (ver tabla 2) para determinar el coeficiente de consenso entre todos los pares de autores posibles utilizando la prueba Kappa Cohen.

\begin{tabular}{|c|c|c|c|}
\hline \multirow{2}{*}{\multicolumn{2}{|c|}{}} & \multicolumn{2}{|c|}{$\begin{array}{c}\text { Presencia del término clave en la definición del } \\
\text { primer autor }\end{array}$} \\
\cline { 3 - 4 } & SI & NO \\
\hline $\begin{array}{c}\text { Presencia del término } \\
\text { clave en la definición } \\
\text { del segundo autor }\end{array}$ & SI & A & C \\
\cline { 2 - 4 } & No & B & D \\
\hline
\end{tabular}

Tabla 2. Tabla de contingencias utilizada para la realización de la prueba de kappa Cohen.

En la tabla de contingencia el valor de $(A)$ está dado por la suma de la cantidad de veces que el término clave coincide en la definición aportada por ambos autores; el valor de (B) sería la suma de la cantidad de veces que el término clave está presente en la definición del primer autor y ausente en la del segundo; el valor (C) la suma de la cantidad de veces en que el término clave está ausente en la definición del primer autor y presente en la del segundo y (D), la suma de la cantidad de veces que el término clave está ausente en las definiciones de ambos autores. 
REDES- Revista hispana para el análisis de redes sociales

Vol.14,\#9, Junio de 2008

http: //revista-redes.rediris.es

Una vez elaborada la tabla de contingencias se determina el índice Kappa Cohen para cada par de autor posible (703) mediante la siguiente fórmula

$$
K=\frac{p_{0}-P_{e}}{1-P_{e}}
$$

donde: Po es la proporción de concordancia observada y Pe es la proporción de concordancia esperada por puro azar. En caso de acuerdo perfecto la proporción de concordancia será 1 , por lo que 1-Pe representa el margen de acuerdo posible no atribuible al azar.

Para calcular la proporción esperada $(\mathrm{Pe})$, el razonamiento es el siguiente: de acuerdo a la tabla de contingencias (ver tabla 2) la probabilidad de que el primer autor utilice el término clave en su definición se puede estimar como f1/n; mientras que la correspondiente probabilidad del segundo autor a utilizar dicho término clave se estimará como $\mathrm{Cl} / \mathrm{n}$. Si se considera que existe independencia entre ambos autores, la probabilidad que coincida en la utilización del mismo térmno clave en su definición de estrategia será entonces el producto de las posibilidades (sucesos independientes). Aplicando el mismo razonamiento se calcula la probabilidad de que se produzca acuerdo entre ambos autores al no emplear el término clave en su definición, y entonces la probabilidad de acuerdo cualquiera de las dos clasificaciones será la suma de ambos valores, esto es:

$$
P_{e}=\frac{f_{1} * c_{1}+f_{2} * c_{2}}{n^{2}}
$$

Para facilitar este proceso que puede ser lento y agotador, se recomienda emplear programas muy potentes como SYSTAT 12.0.

Luego cada valor obtenido por el cálculo del índice de Kappa y se sitúa en una hoja de cálculo de Excel (ver ilustración 5). 
REDES- Revista hispana para el análisis de redes sociales

Vol.14,\#9, Junio de 2008

http://revista-redes.rediris.es

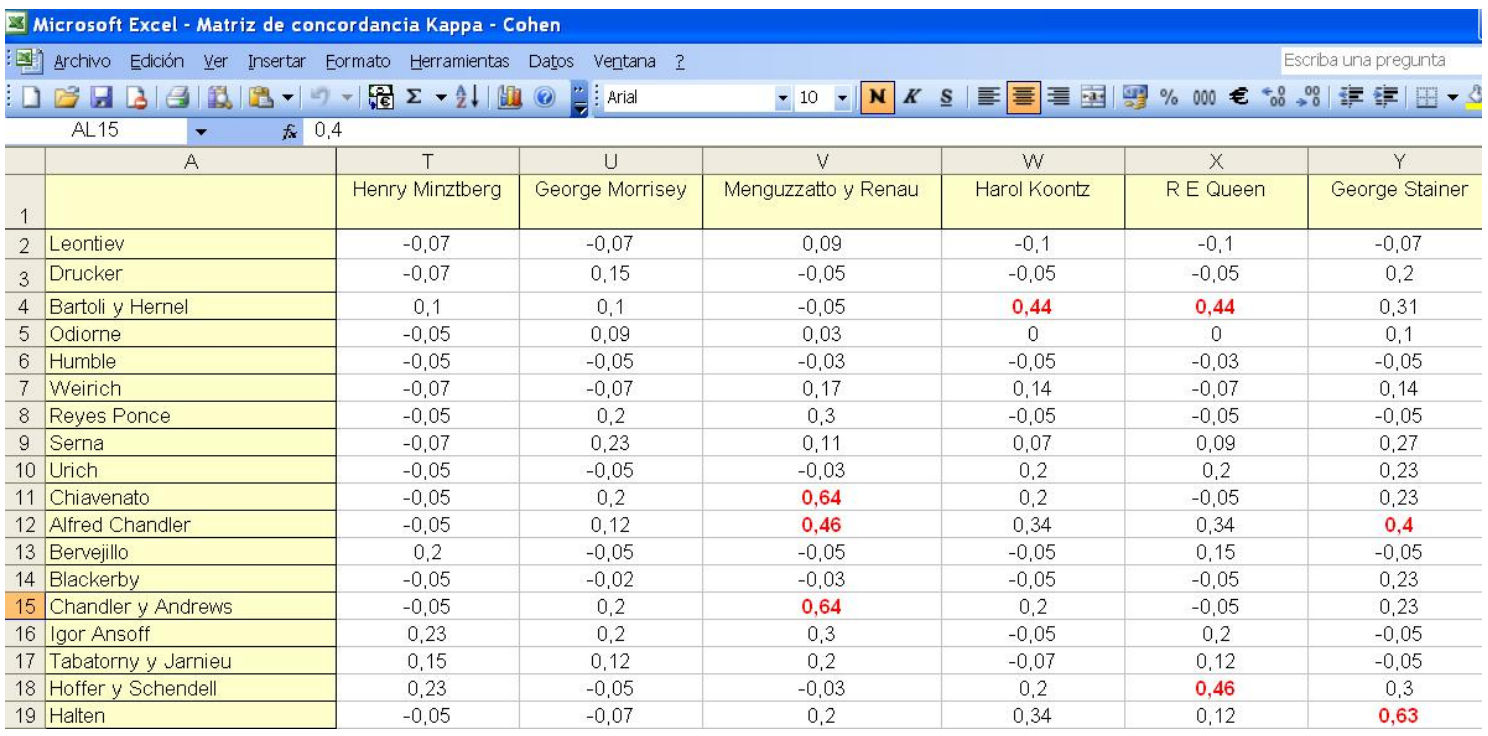

I lustración 5. Parte de la tabla con los índices de Kappa Cohen entre autores de la definición del concepto estrategia.

Una vez calculado el índice de Kappa Cohen para cada par de autores, se emplea cada valor para elaborar una matriz de incidencia tipo 1, para lo cual se considera que existe relación entre dos definiciones si el índice Kappa Cohen es mayor o igual que $0.40(K>0,40)$ y se le asigna el valor de $(1)$, y no existe relación entre dos definiciones si el índice Kappa Cohen es menor que $0,40(K<0,40)$ y se asigna el valor (0) (ver Ilustración 6).

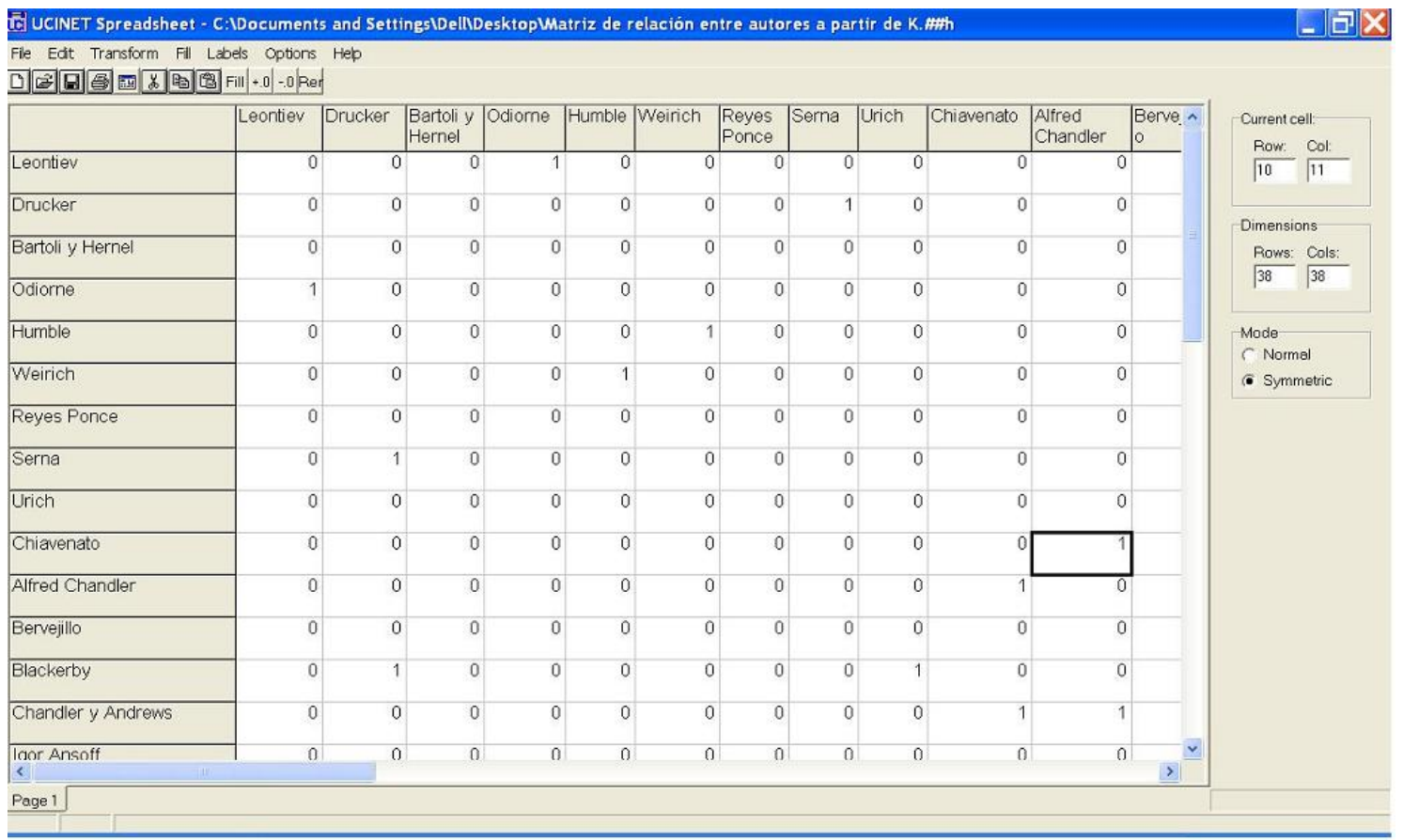

I lustración 6. Parte de la matriz de incidencia a partir del coeficiente de Kappa Cohen. 
REDES- Revista hispana para el análisis de redes sociales

Vol.14,\#9, Junio de 2008

http: // revista-redes.rediris.es

A través del programa NetDraw (Borgatti, Everett, \& Freeman, 1999) se representó gráficamante la matriz.

Por último a través de UCINET 6 (Borgatti, Everett, \& Freeman, 1999) se determinó el grado nodal, la cercanía y la intermediación.

\section{Estructura de la red de actores a partir de los términos claves empleados en la definición del concepto estrategia}

En la ilustración 7 se muestra la red obtenida a través del programa Netdraw. En color azul aparecen los términos claves y en círculos rojos los autores. Como se puede observar los términos claves centrales son empresa, entorno, proceso, objetivos y recursos, lo cual coincide con lo que se pudiera apuntar como la esencia de la de la dirección estratégica como herramienta de gestión empresarial más utilizada en el mundo durante el siglo XX.

El éxito del empleo de la dirección por objetivos difundida por Peter Drucker (Drucker, 1954) en su libro “The Practice of Management" y que se difundió posteriormente por todo el mundo ha influido considerablemente para que la mayoría de los autores lo sitúen como uno de los terminos centrales en sus definiciones de estrategia.

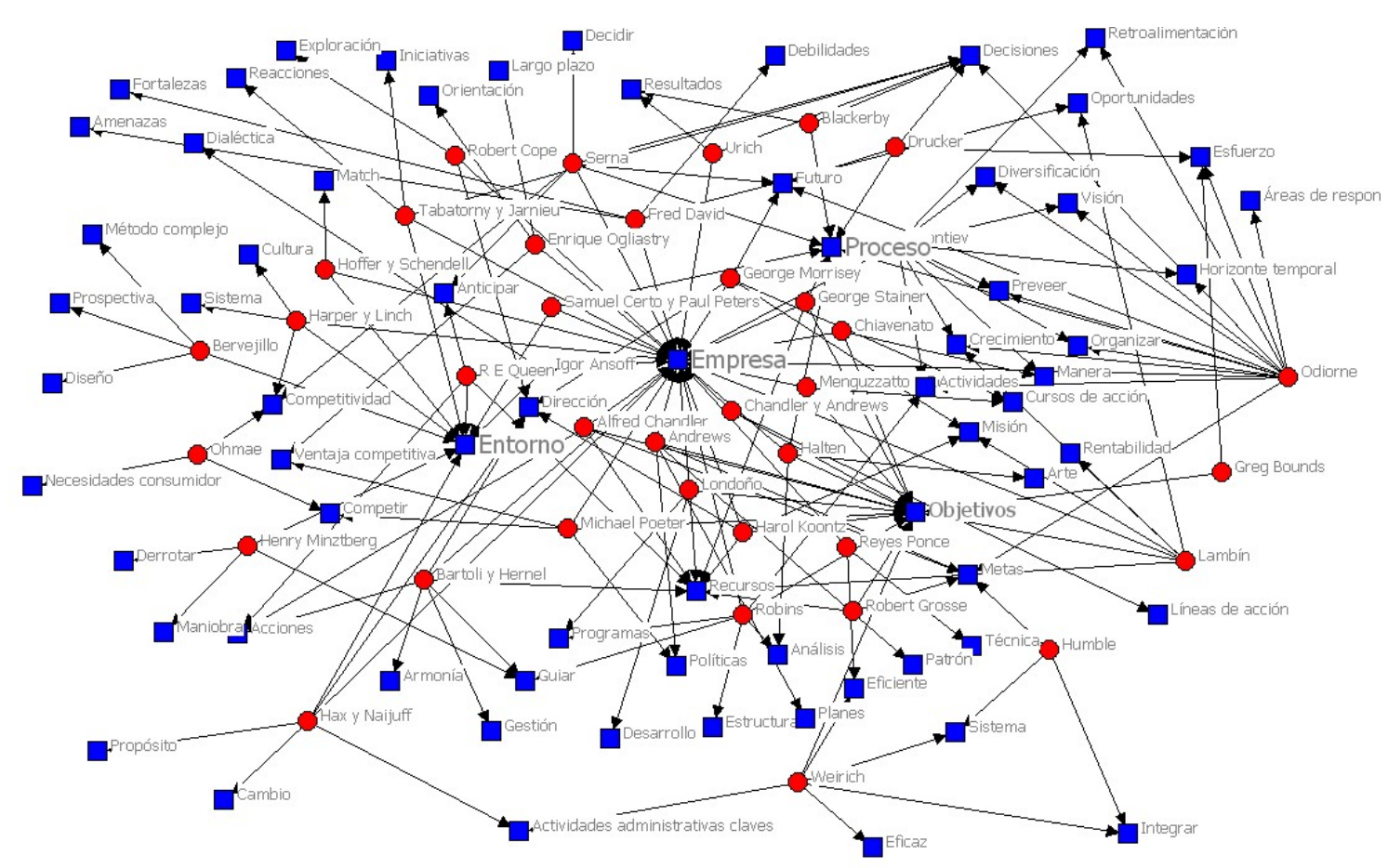

I lustración 7. Grafo de la matriz de los autores y los términos claves empleados en la definicón del concepto de estrategia. 
REDES- Revista hispana para el análisis de redes sociales

Vol.14,\#9, Junio de 2008

http: //revista-redes.rediris.es

Resulta interesante también la regularidad de la presencia de los términos empresa y entorno en la mayoría de las definiciones. La génesis de la expresión de la relación entre ambos fueron expresados inicialmente por Philip Selznick en 1957 (Selznick, 1957), y desarrollados luego por Learned y otros profesores de la Harvard Business School.

El estudio sistemático de esta regularidad nos llevó a fundamentar dicha relación (ver Ilustración 8) como una ley, “ley de interacción dialéctica de la organización con su entorno" (Ronda Pupo, 2003). En la misma se argumentan como supuestos los siguientes: Ninguna organización puede subsistir aislada de su entorno, la imposibilidad de la organización de cambiar la forma de manifestación de los factores externos en el macrontorno, la organización tiene que coexistir y adaptarse a los elementos del microentorno, maniobrar para mantener una homeostasis positiva y por último, la individualidad de la forma de manifestación de los factores externos sobre las organizaciones. Esto quiere decir que lo que se manifiesta como oportunidad para una organización en un determinado sector puede representar una amenaza para otra organización que compite en el mismo.



I lustración 8. Relación organización-entorno.

Otro término que aparecen como central es proceso, que evidencia la estrategia como un ciclo iterativo y en los últimos años se le ha agragado holístico para reflejar la estrateigia como un todo inseparable (Ketchen Jr. \& Palmer, 1999; Martinsons, Everett, \& Chan, 2001). 
REDES- Revista hispana para el análisis de redes sociales

Vol.14,\#9, Junio de 2008

http: // revista-redes.rediris.es

El término recurso también ha ido cobrando fuerza dentro de las tendencias de la estrategia (Lengnick-Hall \& Wolff, 1999), (Chi) y (Powell \& Dent-Micallef, 1997) entre otros. En los últimos años matizado por la aparición de la importancia de los recursos intangibles en las organizaciones ocmo fuente de ventajas competitivas y el desarrollo de modelos para la gestión del conocimiento y el capital intelectual (Bueno, de Pablos, \& Sanchez, 2004), (Camelo-Ordaz, Martín-Alcázar, \& ValleCabrera, 2003).

\section{Estructura de la relación entre los autores que han abordado la definición del concepto estrategia a partir del índice de Kappa}

En la llustración 9 se muestra el grafo de la matriz de incidencia, partiendo del grado de concordancia entre cada par de autor mediante el cáculo del índice de kappa.

Se observa al relación entre las definicones, las cuales se presentan con el nombre del autor que la propone. Como se puede apreciar 6 autores aparecen aislados, de ellos resultan significativos Henry Mintzberg, Kenichi Ohmae y Fred David, que han hecho aportes significativos a la perspectiva teórica de la dirección estratégica; este hecho se justifica debido a que han realizado opciones claras sobre qué es la estrategia y no abordan aristas gerneralemente tratadas por el resto de los autores.

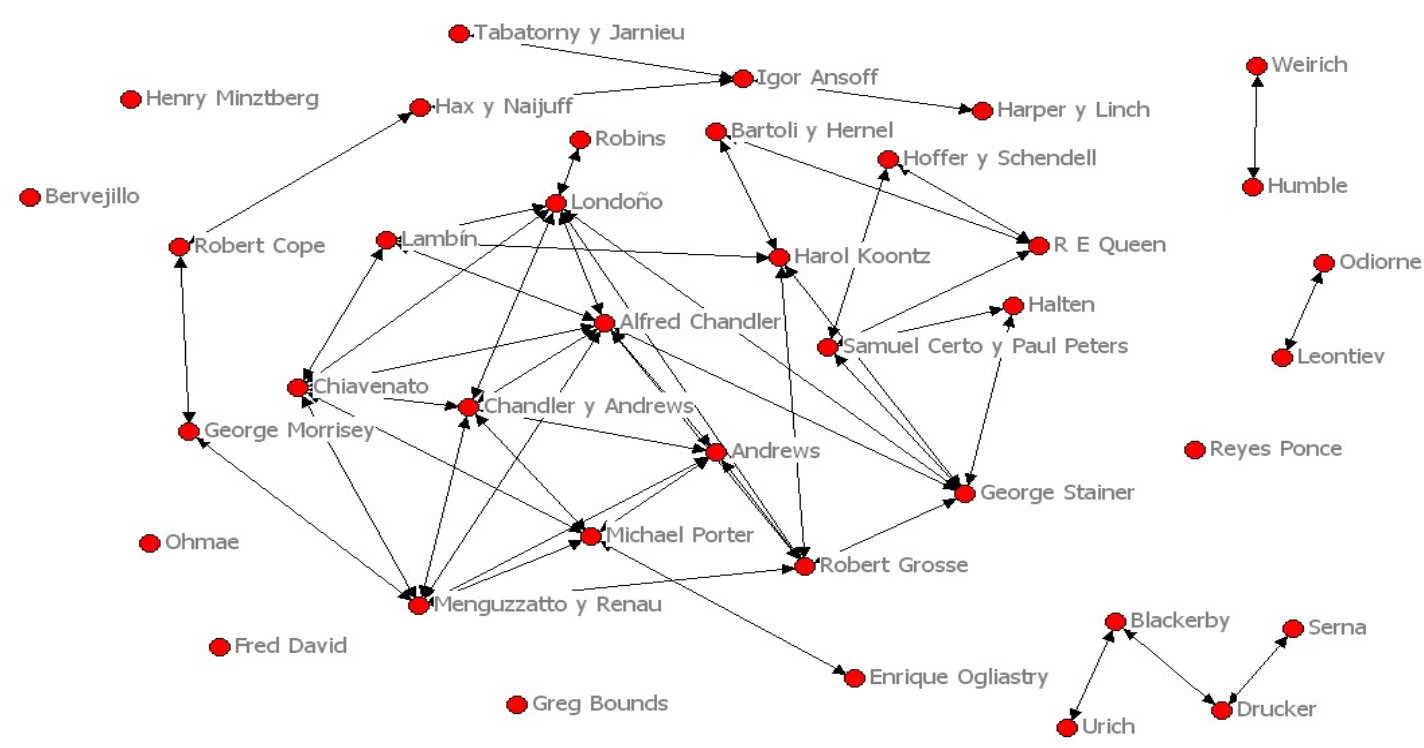

I lustración 9. Grafo de la matriz de las relaciones de los autores de la definición estrategia a partir del índice Kappa. 
REDES- Revista hispana para el análisis de redes sociales

Vol.14,\#9, Junio de 2008

http: // revista-redes.rediris.es

\section{Determinación del grado nodal de la red de actores}

A través del programa UCINET 6 (Borgatti, et.al. 1999) se determinó el grado nodal de la red (ver ilustración 10). Como se puede observar la definición del autor Alfred Chandler es el ego de la misma ( 21 conexiones), es la definición de mayor centralidad, a partir del cual se fue construyendo la red de definiciones que han contribuido al desarrollo de la pespectiva teórica de la dirección estratégica en el campo empresarial.

Este autor se considera el precursor de la dirección estratégica, el mismo demostró en el año 1952 la importancia de la coordinación de los aspectos de la dirección en un solo elemento "la estrategia de la organización" posteriormente, a partir de la experiencia de Chandler, se fue elaborando un conjunto de conceptos desarrollando un nuevo vocabulario en la teoría de la administración, además fue el primero en formular la teoría sobre el análisis de brechas (gap analysis). A través de este análisis se confirma a Chandler como uno de los autores que mayor influencia tuvo en el desarrollo de las aproximaciones teóricas sobre la estrategia empresarial moderna y uno de sus pioneros.

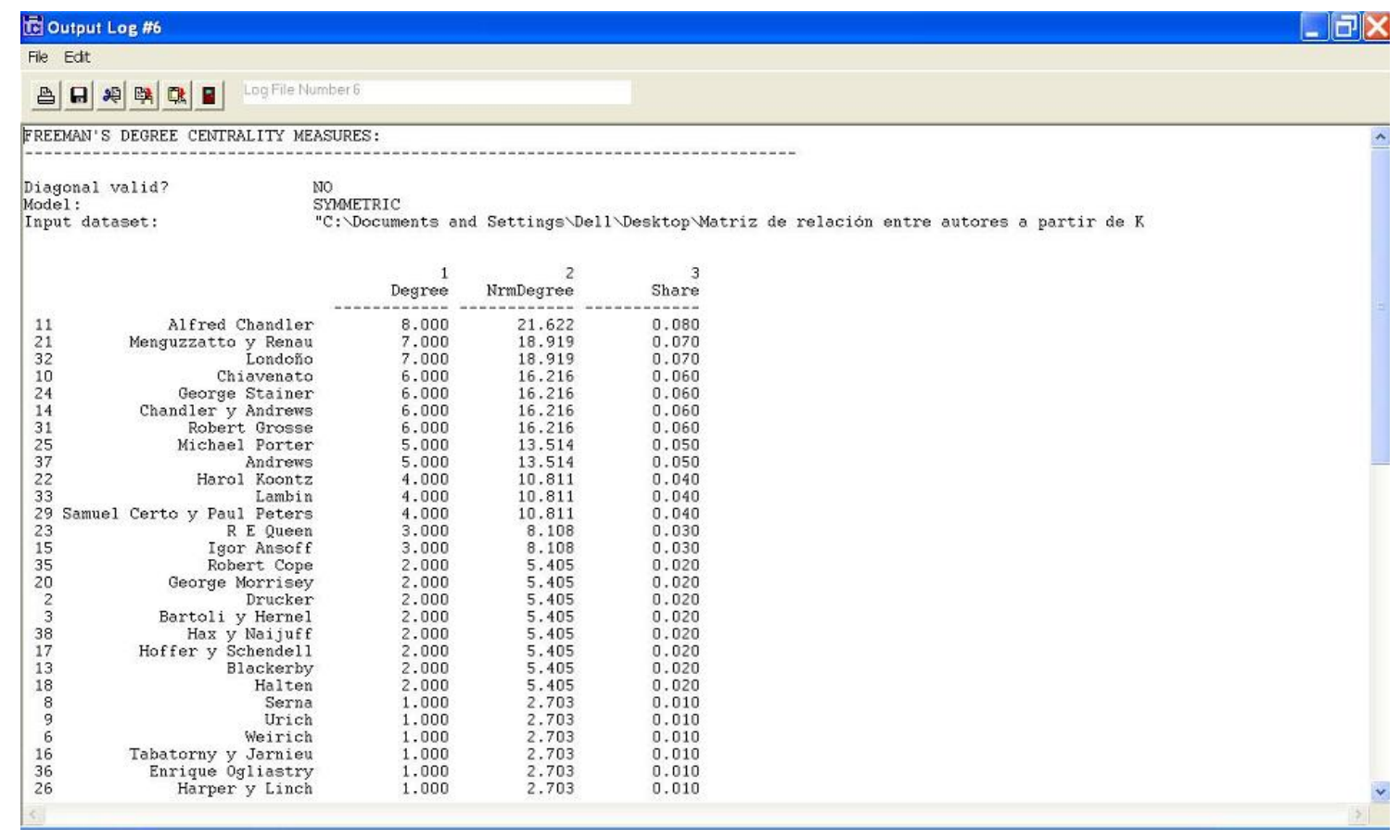

Ilustración 10. Resultados del cáculo del grado nodal.

El rango promedio de la red es 12,7 y la mayor cantidad de lazos es de 28 . (Ver ilustración 11). 
REDES- Revista hispana para el análisis de redes sociales

Vol.14,\#9, Junio de 2008

http: //revista-redes.rediris.es

\section{DESCRIPTIVE STATISTICS}

$\begin{array}{lrrrr} & & 1 & 2 & 3 \\ & & \text { Degree } & \text { NrmDegree } & \text { Share } \\ 1 & \text { Mean } & --1.454 & 12.787 & 0.026 \\ 2 & \text { Std Dev } & 2.349 & 8.698 & 0.018 \\ 3 & \text { Sum } & 131.240 & 485.894 & 1.000 \\ 4 & \text { Variance } & 5.519 & 75.654 & 0.000 \\ 5 & \text { SSQ } & 662.994 & 9087.829 & 0.038 \\ 6 & \text { MCSSQ } & 209.732 & 2874.853 & 0.012 \\ 7 & \text { Euc Norm } & 25.749 & 95.330 & 0.196 \\ 8 & \text { Minimum } & -1.160 & -4.295 & -0.009 \\ 9 & \text { Maximum } & 7.720 & 28.582 & 0.059\end{array}$

I lustración 11. Estadística descriptiva del cálculo del grado nodal.

\section{Grado de intermediación entre actores que componen la red}

A través del cálculo de intermediación entre las definiciones (ver ilustración 12) se determinó que la definición elaborada (Menguzzatto \& Renau, 1994) son los puentes de la red ya que conectan al mayor número de autores, este resultado resultará controvertido para los investigadores y estudiosos de la epistemología de la dirección estratégica, el mismo pudiera obedecer a que la definición concebida por Menguzzato y Renau fue trabajada posterior a 1984, etapa en que ya había sido abordada a nivel internacional la misma por varios autores y se nutre de muchas definiciones anteriores; no obstante, es meritorio, el trabajo de la autora Martina Menguzzato, la cual, en unión de su esposo Renau, desarrolló una conceptualización de la dirección estratégica, sobre todo en la década de los 80 del pasado siglo, que ha sido muy seguida en Sur América principalmente en Brasil y Latinoamérica sobre todo en Cuba. 
REDES- Revista hispana para el análisis de redes sociales

Vol.14,\#9, Junio de 2008

http: //revista-redes.rediris.es

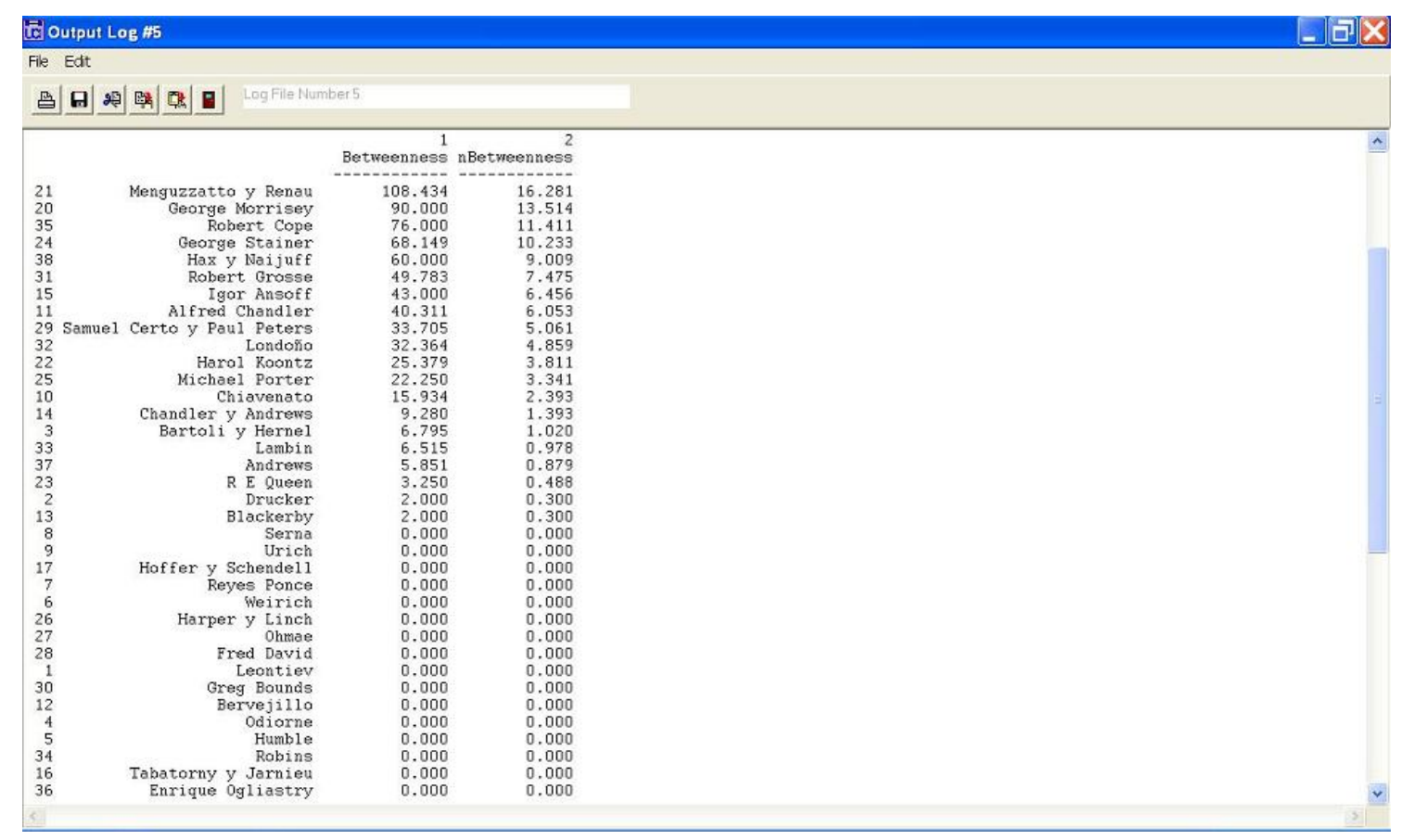

I lustración 12. Resultados del cálculo del grado de intermediación entre autores.

\section{Determinación de la cercanía entre los actores de la red}

En la ilustración 13 se muestra los valores del cálculo de la cercanía entre los actores de la red. Como se puede apreciar las definiciones de Alfred Chander y Menguzzato y Renau son las que cuentan con un mayor grado de cercanía del resto de la red. En el caso de la definición de Menguzzato, sin restar su valor, por la razones que han sido expuestas con anterioridad.

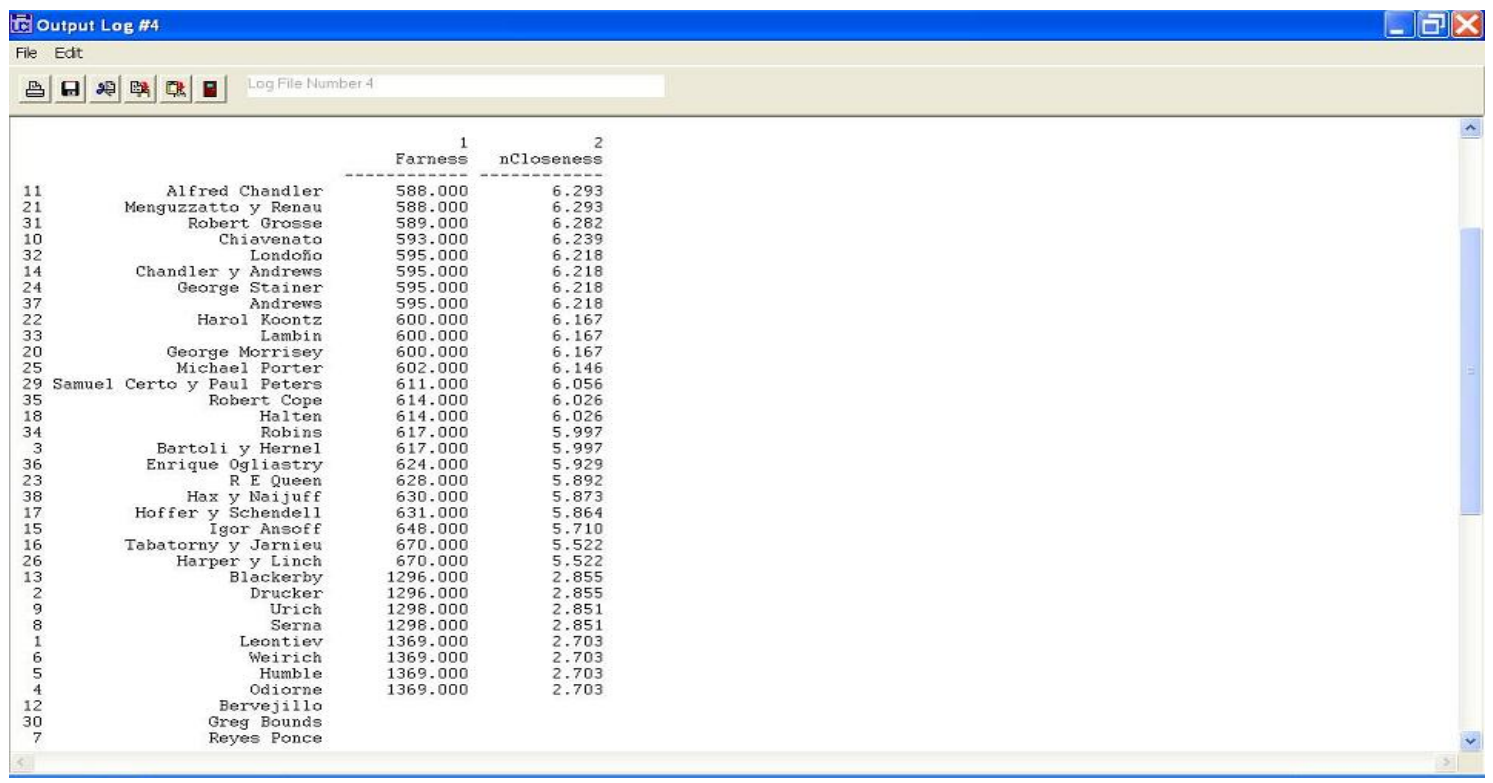

I lustración 13. Resultados del cálculo de la cercanía entre autores. 
REDES- Revista hispana para el análisis de redes sociales

Vol.14,\#9, Junio de 2008

http: // revista-redes.rediris.es

\section{Conclusiones}

El estudio realizado confirma que existe un alto nivel de dispersión en la perspectiva teórica de la dirección estratégica y se pueden identificar claramente visiones diferentes sobre un mismo tema. Los autores puntualizan, en su definición, los aspectos que consideran esenciales, lo que hace que no exista consenso en lo que es realmente la estrategia empresarial de manera que sea generalmente aceptada.

Como se puede apreciar a pesar de los múltiples aportes que han realizado todos los autores que han dedicado esfuerzos a la investigación del tema de la estrategia empresarial aún no aparece un paradigma que sea generalmente aceptado sobre el cual se contruya una perspectiva teórica sólida, lo cual enfatiza la juventud de este campo de investigación y la necesidad de continuar la realización de investigaciones teóricas sobre el mismo.

El análisis de redes sociales brinda técnicas que coadyuvan a evaluar la perspectiva teórica de la estrategia empresarial de una manera práctica y facilita ver los aspectos esenciales en los cuales se ha centrado el desarrollo de los diferentes aportes por los autores que han abordado el tema. 
REDES- Revista hispana para el análisis de redes sociales

Vol.14,\#9, Junio de 2008

http: // revista-redes.rediris.es

\section{Bibliografía}

Andrews, K. R. (1962). The concept of corporate strategy. New York: Dow - Jones Irwin.

Ansoff, I. (1962). Corporate Strategy. New York: McGaw Hill.

Ansoff, I. (1976). La estrategia de la empresa. Bilbao: Editorial Universidad de Navarra.

Borgatti, S. P., Everett, M. G., \& Freeman, L. C. (1999). UCINET 6.0 Version 1.00. Natick: Analytic Technologies.

Bounds, G., Yorks, L., Adams, M., \& Ranney, G. (1994). Total Quality Management. Madrid: McGraw Hill.

Certo, S., \& Peters, P. (1994). Dirección Estratégica. Madrid: Ed. Irwin.

Chandler, A. (1962). Strategy and Structure: Chapters in the History of Industrial Enterprise. New York: Doubleday.

Chiavenato, I. (1986). Introducción a al teoría general de la administración. México: Ed. McGraw Hill.

Clausewitz, K. V. (1977). De la Guerra (2 ed.). México: Editorial Diógenes, SA.

Cope, R. (1991). El plan estratégico: Haga que la gente participe. Madrid: Ed. Legis.

David, F. (1991). La gerencia Estratégica. Legis.

Del Mazo Pérez, L. M. (1998). Planeación Estratégica en el centro de estudios de tecnologías avanzadas. ISPJAE, La Habana.

Drucker, P. (1954). The Practice of Management. New York: Harper \& Row.

Foleiro, L. (2005). Innovation Management. Engineering Management, 15(5), 48.

Grosse, R. (2000). Thunderbird On Global Business Strategy. New York: J hon Wiley and Sons.

Harper, \& Linch. (1992). Valoración de puestos y sistemas retributivos e incentivos. México: Harper \& Linch.

Hax, A., \& Majluf, N. (1997). Estrategias para el liderazgo competitivo. México: Ediciones Granica S.A.

Humble, J. W. (1977). La dirección por objetivos: Sistemas, experiencias. Aplicaciones prácticas. México: Asociación para el progreso de la Dirección.

Leontiev, L. A. (1970). Fundamentos de la economía política marxista. Moscú: Ed. Agencia de Prensa Novosti.

López, P. B. (2005). Propuesta de un plan de acción para el gobierno local de la zona turística de Viñales, en materia de turismo de naturaleza. Tesis de Maestría, Universidad de Pinar del Río, Pinar del Río. 
REDES- Revista hispana para el análisis de redes sociales

Vol.14,\#9, Junio de 2008

http: // revista-redes.rediris.es

Machiavelli, N. (1998). The Prince. UK: Oxford University Press.

Menguzzato, M., \& Renau. (1994). La dirección estratégica de la empresa un enfoque innovador del management. (Vol. 1). Brasil.

Mintzberg, H., \& Queen, J. B. (1997). El proceso estrátegico: conceptos, contextos y casos. NY: Prentice Hall.

Morrisey, G. (1993). El pensamiento estratégico.Construya los cimientos de su planeación. Madrid: Ed. Prenticehall Hispanoamericana.

Nerur, s. P., Rasheed, a. A., \& Natarajan, v. (2008). The Intellectual Structure of the Strategic Management Field: an Author Co-citation Analysis. Strategic Management J ournal, 29, pp 319-336.

Newman, J. V., \& Morgenstern, O. (1964). Theory of Games and Economic Behavior (5 ed.): University of Michigan Press.

Odiorne, G. (1995). Administración por objetivos. Nuevo sistema para la dirección. México: Ed. Limusa.

Ogliastri, E. (1992). Manual de Planeación Estratégica. (7ma. ed. Vol. 1). Colombia: Ediciones Uniandes.

Ohmae, K. (1982). The Mind of Strategist: The Art of Japanese Business. Madrid: McGraw Hill Profesional.

Porter, M. E. (1991). Towards a Dynamic Theory of Strategy. Strategic Management J ournal, 12(Special Issue), p: 95.

Powell, T. C., \& Dent-Micallef, A. (1997). Information Technology as Competitive Advantage: The Role of Human, Business, and Technology Resources. Strategic Management J ournal, 18(5), 375-405.

Quinn, J. B. (1985). The Strategic Process. Concept, Context, Cases (2da ed.). New York: IRWIN.

Ramos-Rodriguez, A.-R., \& Ruiz-Navarro, J. (2004). Changes In The Intellectual Structure Of Strategic Management Research: A Bibliometric Study Of The Strategic Management J ournal, 1980-2000. Strategic Management J ournal, 25, 981-1004.

Reyes Ponce, A. (1990). Administración por Objetivos. México: Ed. Limusa.

Robbins, S. (1993). Comportamiento Organizacional. Conceptos, controversias, aplicaciones. México: Ed. Prentice Hall.

Ronda Pupo, G. (2003). Modelo de dirección estratégica para organizaciones de Seguridad y Protección en el contexto cubano. Unpublished Tesis en Opción al título científico de Doctor en Ciencias Técnicas., ISPJ AE, La Habana.

Schendel, D., \& Hofer, C. (1979). Strategic Management: Little, Brown and Co.

Selznick, P. (1957). Leadership in Administration: A sociological Interpretation: Row Peterson.

Serna, H. (1994). Planeación y dirección estratégica. Colombia: Editorial Legis. 
REDES- Revista hispana para el análisis de redes sociales

Vol.14,\#9, Junio de 2008

http: // revista-redes.rediris.es

Steiner, G. A. (1965). How to Assure Poor Long-Range Planning for Your Company. California Management Review, 7(000004), p 93.

Tabatorny, P., \& Jarniou, P. (1975). Les systemes de Gestion: politiques et structures. París: PUF.

Tzu, S. (1883). The Art Of War (James Clavel ed.). New York.

Weirich, H. K. a. H. (1993). Elementos de Administración. (Quinta ed.). New York: McGraw Hill.

Wolf, J., \& Egelhoff, W. G. (2002). A reexamination and extension of international strategy-structure theory. Strategic Management Journal, 23(2), P: 181. 